\title{
A study of tilt change recorded from July to October 2006 at the Phlegraean Fields (Naples, Italy)
}

\author{
Ciro Ricco, Ida Aquino, Sven Ettore Borgstrom and Carlo Del Gaudio \\ Osservatorio Vesuviano, Istituto Nazionale di Geofisica e Vulcanologia, Sezione Napoli, Napoli, Italy
}

\begin{abstract}
The tiltmetric dataset of Phlegraean Fields area showed a discrete correlation with the volcanic dynamics, suggesting that tiltmetric monitoring is important for the surveillance of active volcanic areas. Tilt data recorded in 2006 at 2 stations belonging to the monitoring network of the Osservatorio Vesuviano (INGV, National Institute for Geophysics and Volcanology, Italy) in the Phlegraean Fields are discussed in this paper. The acquired signals have shown a strong tiltmetric inversion that took place from the end of July 2006. After correcting tilt variations to eliminate the influence of temperature (influencing $90 \%$ of the signal at OLB station, hereafter OLB) a significant value of the tilt still remains. This change is related to a local inflation episode lasting 3 months, during an unrest phase that started 2 years before. It is interesting to note that tilt amplitude is much greater at OLB than the slope of the displacement field predicted by the theoretical inflation models, but data show that this field is not homogeneous and in some areas very tilted. Moreover, in the last days before the end of tilt inversion, a low energy seismic swarm happened at about $1 \mathrm{~km}$ of distance from the tiltmetric station by hundreds of VT (Volcano-Tectonics) and LP (Long-Period) events.
\end{abstract}

Key words monitoring - tilt network - ground deformation - spectral analysis - decorrelation methodology

\section{Introduction}

The Phlegraean Fields caldera is the largest volcano in the Phlegraean Volcanic District (including also the islands of Procida and Ischia), located to the west of the city of Naples, Italy.

The morphology of the area is the result of deformation events related to regional tectonics and to volcano-tectonics.

The Phlegraean Fields area was generated by 2 major collapses related to the Campanian

Mailing address: Dr. Ciro Ricco, Osservatorio Vesuviano,Istituto Nazionale di Geofisica e Vulcanologia, Sezione Napoli, Via Diocleziano 328, 80124 Napoli, Italy; e-mail: ricco@ov.ingv.it
Ignimbrite (39 ka) and Neapolitan Yellow Tuff (15 ka) eruptions, respectively (Orsi et al., 2004), with the last eruption which dates back to 1538 . Its magmatic system is still active with fumarolic activity and ground deformations, the latter characterized by an almost bell-shaped form which covers an almost circular area with a radius of $6 \mathrm{~km}$ centred in the town of Pozzuoli (Orsi et al., 1999).

Major uplifts occurred in 1969-1972 (with a maximum ground uplift of about $170 \mathrm{~cm}$ ) and 1982-1984 (with a maximum uplift of about 180 cm) (Corrado et al., 1977; Berrino et al., 1984). Since 1985 the Phlegraean Fields area has been undergoing a subsidence phase, with only short uplift events recorded in 1989, 1994, 2000 and 2004-2006, the last being the object of this paper.

The deformation history has been recorded in detail by high precision levelling measurements carried out since the end of the sixties, allowing us to create a reference dataset. 


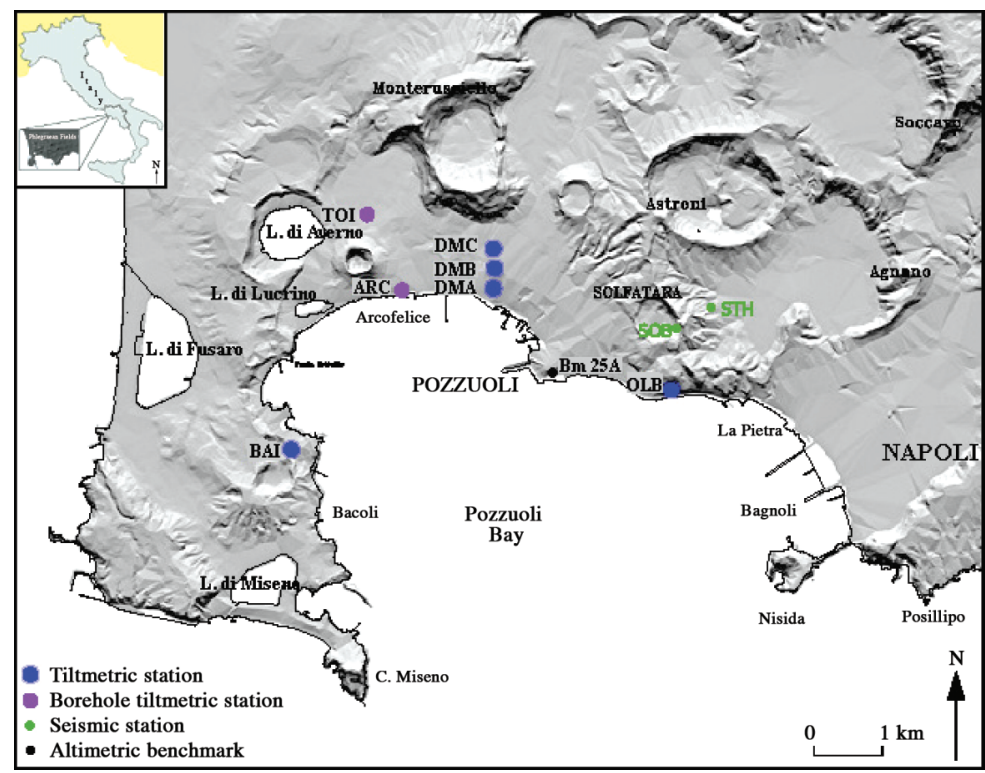

Fig. 1. The tiltmetric network of the Phlegraean Fields (Naples, Italy).

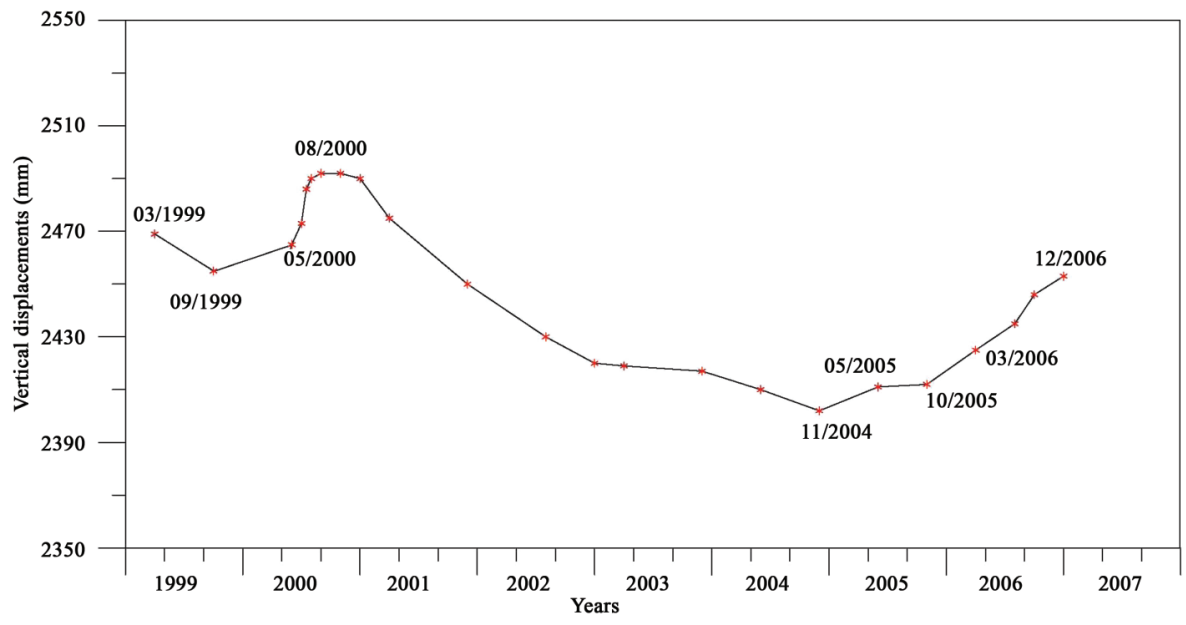

Fig. 2. Height variation of benchmark 25A in the time interval March 1999-December 2006 showing the trend of the vertical ground deformation in the maximum uplift area close to Rione Terra in Pozzuoli.

Moreover, in the last ten years the tiltmetric monitoring network (fig. 1) has provided additional information related to the angular component of strain in the different measuring points and has allowed us to follow the evolu- tion of the deformation phenomenon interesting the Phlegraean Fields.

Such a phenomenon can be decomposed in a subsidence phase with decreasing velocity on which an uplift measured by all the monitoring 
networks between spring and summer 2000 recorded. Moreover, in the last 2 years a significant change occurred in both velocity and intensity of the displacement (fig. 2) and ground tilt fields (Ricco et al., 2005) which gave rise at the end of July 2006 to the uplift described in the present work.

With regard to the interferometric measurements carried out in the Phlegraean Fields in the period 2005-2006 (Berardino et al., 2007) a ground deformation was pointed out in a good agreement with tiltmetric data, the latter indicating an uplift already from the last months of 2004.

The reason this event was not pointed out by SAR Interferometry at its very beginning, lies in the limit of the resolution of the $C$ band used by the SAR sensor, when dealing with very low deformation rates, with a discontinuous temporal trend.

By contrast, the deformation rate that occurred from the second half-year of 2005 allowed such an investigation indicating, from the results of ascending data (Image Swath 2), a line of sight deformation of more than $4 \mathrm{~cm}$ from mid-2005 to the end of 2006 in the maximum deformation area, close to Pozzuoli Harbour and the surroundings.

Also the interferometric processing of descending data confirms the same deformation rate for the same period, with a deformation pattern extending in this case also towards the east.

The different areal distribution of deformation, when comparing data from ascending and descending tracks, rises from the presence of an already known planimetric component of ground motion in the area (Lanari et al., 2004).

\section{Description of the measuring points and sensors}

The Phlegraean tiltmetric network has 7 stations, 5 of which equipped with surface sensors (DMA, DMB, DMC, BAI and OLB) and 2 boreholes (TOI and ARC). The latter are equip-ped with sensors model AGI 722 (bi-axial, bubbletype, borehole tiltmeters, manufactured by Applied Geomechanics), the others with sensors model AGI 702 (bi-axial, bubble-type, short baselength platform tiltmeters).
Tilt variations are measured along 2 orthogonal directions $X$ and $Y$ aligned to west-east and north-south axes; the sensors have an angular range of $\pm 800 \mu \mathrm{rad}$ in high gain, a resolution of $0.1 \mu \mathrm{rad}$, a sensitivity of $10 \mathrm{mV} / \mu \mathrm{rad}$, a repeatability of $1 \mu \mathrm{rad}$ and a maximum non linearity of $1 \%$.

The tiltmeters are also equipped with a temperature sensor with resolution of $0.1^{\circ} \mathrm{C}$; besides, DMA recorded also the atmospheric pressure.

Data acquisition system is the HANDI-LOGGER model 798-A of Geomechanics, equipped with a datalogger CR10X collecting and storing the data from tiltmeters at a sample rate of $12 \mathrm{cph}$ $\left(h^{-1}\right)$. The station also acquires the supply voltage before the telematic connection with the Monitoring Center at Osservatorio Vesuviano in Naples.

OLB and DMB recorded a significant rotation of the tilt vector clearly indicating both the beginning and the end of the uplift.

DMA and ARC also recorded the event but the decorrelated data are less clear; on the contrary, TOI and BAI do not provide useful information while DMC was out of order.

With respect to the benchmark (bm) 25A of the network, the tilt stations are located respectively: DMA $1.6 \mathrm{~km}$ NNW, DMB $1.8 \mathrm{NNW}$, BAI 4 WSW, TOI 3.6 NW, ARC 2.7 NW and OLB 1.5 ESE (fig. 1).

OLB was set up during the first months of 2006 in a no longer used railway tunnel developing E-W, $90 \mathrm{~m}$ away from the coast beneath Mount Olibano (Pozzuoli); the tiltmetric sensor was located in a well drilled at depth of $1 \mathrm{~m}$, $150 \mathrm{~m}$ away from the entrance of the tunnel.

DMB is located in a tunnel about $800 \mathrm{~m}$ long and 13 to $22 \mathrm{~m}$ deep along a NNE-SSW direction close to Pozzuoli; the sensor was located about $750 \mathrm{~m}$ away from the coast. This site has been monitored since 1991 but in May 2004 the acquisition system was replaced (Aquino et al., 2006).

\section{Analysis of the recorded data}

Before analysing the recorded signals it must be stated that tiltmetric monitoring, also allowing the availability of very long data sequences, also records, together with the endogenous process which is the aim of the measurement itself, other 
effects partially correlated to each other, like the strain induced on the ground by temperature and atmospheric pressure changes, by rain, etc.

As it is not possible to simply apply filtering of the periodicities due to such phenomena as their meaningful spectral bands often coincide with those characterizing the process under investigation, long enough time-series shall be used to allow the comparison among signals recorded in different years in order to detract seasonal effects.

For OLB 9 months of data are available till now (starting from February 2006) so the pattern of the yearly ground tilt cannot be retrieved; nevertheless the sudden change in both azimuth and modulus of the tilt vector is clear from the tilt plots reported in fig. 3 .

Neither the sensor malfunction nor the ground settling are responsible for this change, as the signal was immediately analysed (so excluding instrumental failure) and the compactness of the well that contain the tool verified.

Sector (1) related to the time interval February 26-July 28 records an angular deformation of $35 \mu \mathrm{rad}$ in N60W direction (with a temperature increase of $5.4^{\circ} \mathrm{C}$ ). Sector (2) related to the time interval July 28-October 31 shows a significant increase in the resultant vector rising up to $421 \mu \mathrm{rad}$ in N55E direction (with a temperature decrease of $1.5^{\circ} \mathrm{C}$ ). Sector (3) related to the time interval October 31-December 11 finally points out a further tiltmetric change of $2.6 \mu \mathrm{rad}$ in N06E direction (with a temperature decrease of $1.3^{\circ} \mathrm{C}$ ) (fig. 4).

As shown by sectors (1), (2) and (3) of fig. 4, also DMB (located about $2.3 \mathrm{~km} \mathrm{NW}$ from OLB) recorded a clear tiltmetric change in the
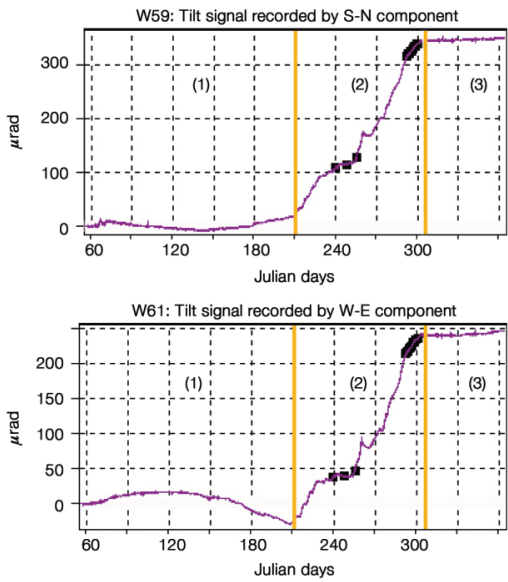
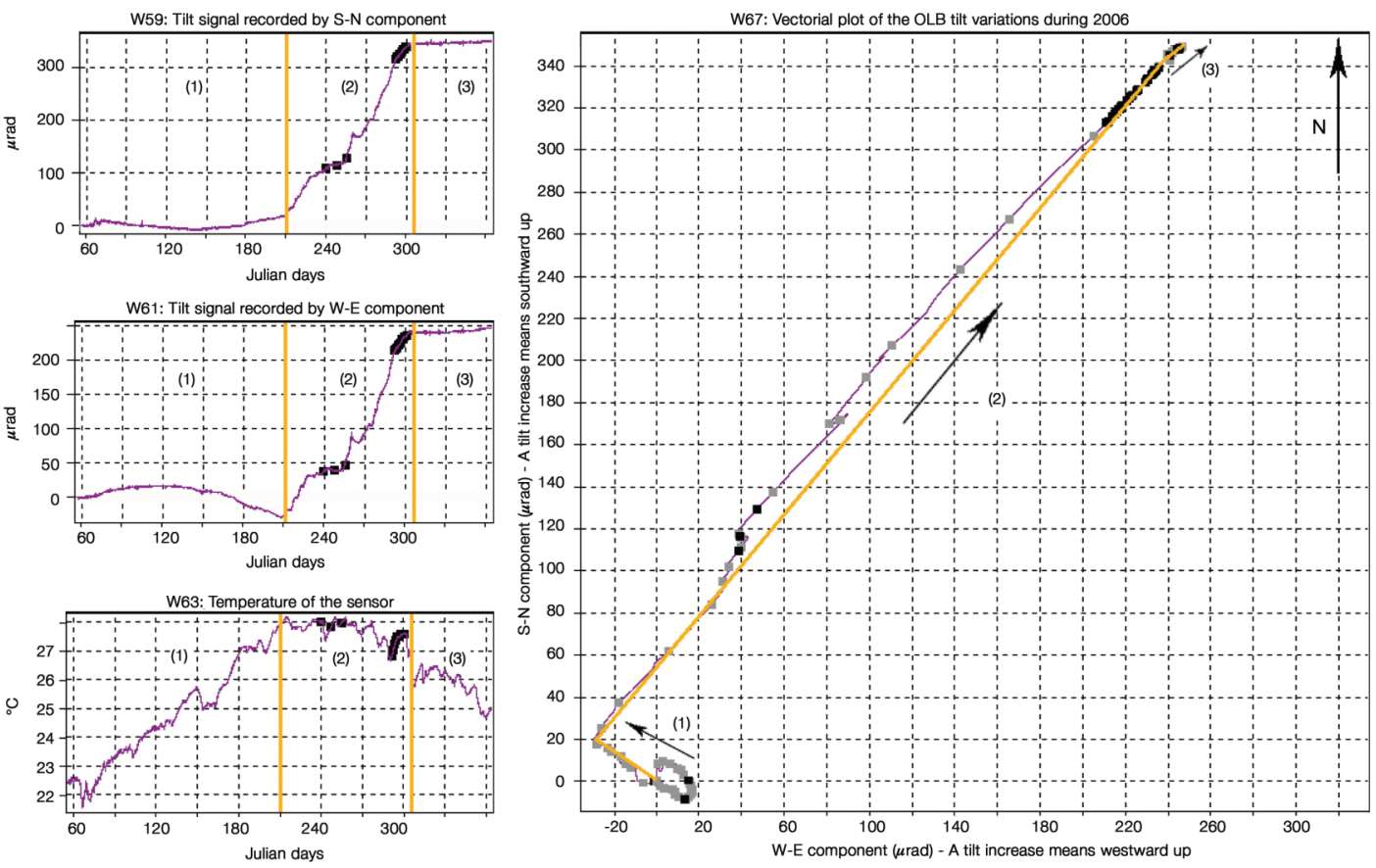

Fig. 3. Working sheet of OLB in Dadisp environment showing the recorded tilt. Windows 59, 61 and 63 report in violet respectively the signals acquired by NS and EW component and temperature of the tilt sensor. In window 67 the resultant vector of each signal (previously submitted to a 1-day simple moving average) is drawn in violet on which grey squares have been superimposed every 5 days. Black squares represent seismic events recorded at STH seismic station, yellow lines delimit the sectors before, during and after the inversion; black arrows were inserted afterwards to facilitate plot reading and point towards the descending area. 

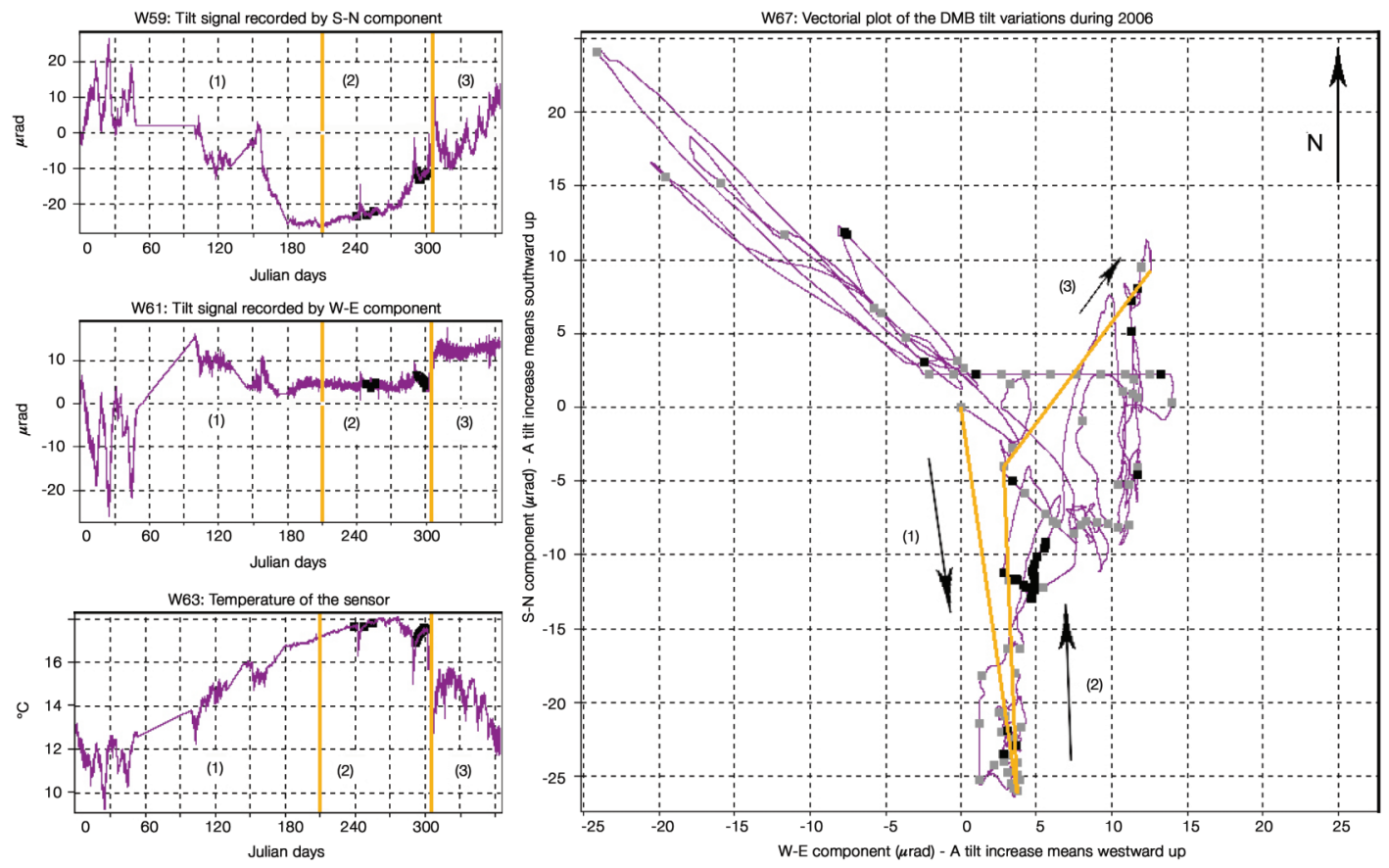

Fig. 4. Signals recorded at DMB (for explanations see fig. 3).

last year, from $26.5 \mu \mathrm{rad}$ in S08E direction in the time interval February 26-July 28 (with a temperature increase of $4.5^{\circ} \mathrm{C}$ ) to $21.1 \mu \mathrm{rad}$ in N02E direction in the time interval July $28-\mathrm{Oc}-$ tober 30 (with a temperature decrease of $1.1^{\circ} \mathrm{C}$ ) and (again) to $8.4 \mu \mathrm{rad}$ in N33E direction in the time interval October 31-December 11 (with a temperature decrease of $1.9^{\circ} \mathrm{C}$ ).

It was not possible to emphasize the inversion on the signals acquired by the stations TOI, ARC and DMA while only the data of the last 2 stations, after decorrelation, allowed us to recognize the event.

Change recorded at OLB was never seen before in the signals acquired in the last years by the other stations, nor do the response to site effects (surface slope heterogeneities, cavity effect in stress propagation) (Harrison, 1976) justify its entity; the one recorded at DMB is on the contrary lower and still lower are tilt variations recorded by the other stations.

Such a discrepancy can be related to both the distance of the deformation source and the temperature (Ricco et al., 2003). As to temperature, it can be seen that the 2 observed stations, which are in quadrature with respect to the maximum uplift area, are affected by a similar environmental thermal variation (at least on a long term period) but in spite of this they give different responses in different spectral bands.

Moreover, the influence of weather conditions like atmospheric pressure (Dal Moro and Zadro, 1998) and rain (Westerhaus and Welle, 2002) on the tilt signals was not able to produce the observed variation.

\section{Signals study in the spectral domain}

The power spectral density (psd) of the signals shows that the amplitude of the solar diurnal component $S_{1}$ observed at DMB is 7 times larger than at OLB, the OLB component suffering the influence of the daily thermal wave less (W90 and W81 in fig. 5). On the contrary, as to the tidal components, the lunar diurnal compo- 

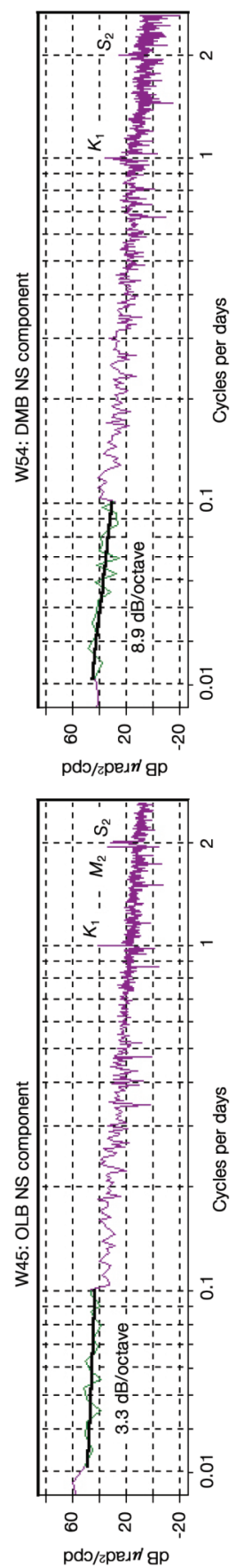

pdo/zpedr ap
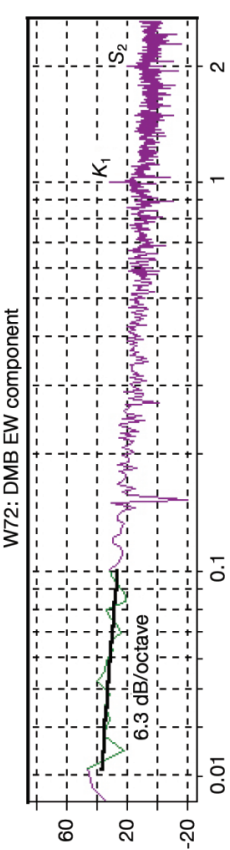

pdo/zpeג gp

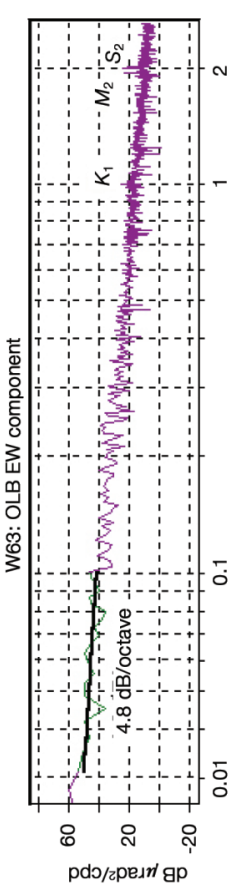

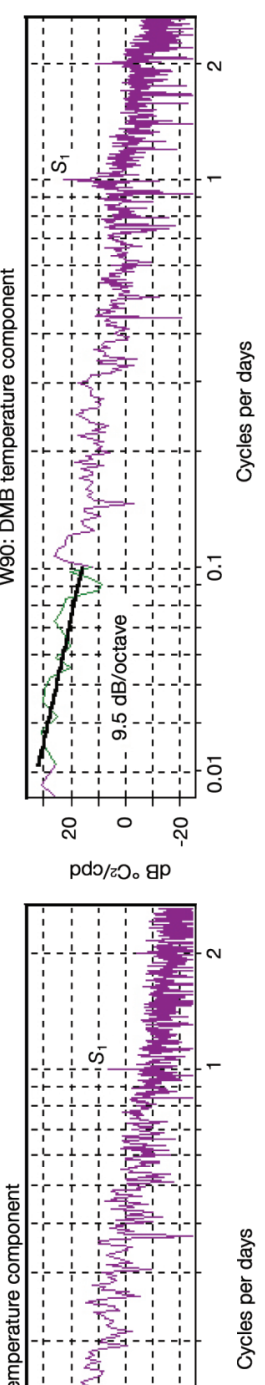

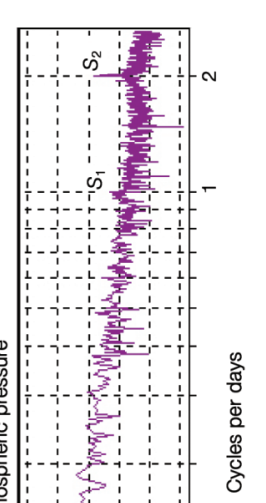

率

远

है을

需.

ป

느응

르

$\dot{0}$

范范

근

을

름

क

元

키

등

흘

층

๑

只

호을

ต 증

○寻

츨

귱

잉

믈

袍

क्षิति

क

हैं

ธี

륨월

巻 की

栥造

늘

过产

전

苍坖芩

क 咨电

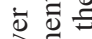

ว 흘

மं О ष

車焉 
nent $K_{1}$ and the principal lunar semidiurnal component $M_{2}$ present at OLB an amplitude 1.9 and 7.5 times greater respectively than DMB on the NS component (W45 and W54) whereas, on the EW component, the $K_{1}$ value is the half the corresponding value of DMB and the $M_{2}$ value is 6.9 times greater (W63 and W72).

Moreover the NS/Te and EW/Te spectral ratios for the $K_{1}$ are respectively equal to 56 (W45 and W81) and 8.8 (W63 and W81) at OLB and to 4.3 (W54 and W90) and 2.6 (W72 and W90) at $\mathrm{DMB}$.

The tidal effect is therefore greater at OLB and the direction in which it prevails is NS whereas the thermal component modulates more the tiltmetric signals of DMB. Both stations on the contrary measure the atmospheric pressure changes and such an effect can be seen in the principal solar semidiurnal component $S_{2}$ present in all the spectra but particularly in that of pressure. It was verified that the greater oscillation inside the atmospheric tide corresponds to a semi-diurnal solar cycle which greatly amplifies the harmonic $S_{2}$ (W99).

Moreover, it was decided to investigate also the long period band (fortnightly to monthly) of the spectra in which the lunar monthly component $M_{m}$ and lunisolar fortnightly component $M_{f}$ usually appear to estimate the correlation degree between tilt and weather changes. The mean increase in energy inside the interval between 10 and 32 days was therefore computed, with a least square approach, by a power law like $P_{f}=P_{0}\left(f / f_{0}\right)^{\gamma}$ (Wyatt et al., 1988) in which $P_{f}$ and $P_{0}$ terms represent the spectral densities of the interval extremes and the $\left(f / f_{0}\right)$ ratio normalises the frequencies to the highest one $f_{0}=0.101 \mathrm{cpd}^{(\text {days }}{ }^{-1}$, fig. 5).

The energy contribution of the temperature estimated between 10 and 32 days is similar at DMB (W90) and OLB (W81) even if the $M_{f}$ component is lower than $M_{m}$ at OLB $(11.2 \mathrm{~dB} /$ /octave) in comparison with DMB (9.5). Tilt signals have higher amplitude at OLB (W45 and W63) compared to DMB (W54 and W72) but in this case the $M_{f}$ component is higher than $M_{m}$ at OLB (3.3 and 4.8) in comparison with DMB (8.9 and 6.3). Moreover, in the same time interval, the atmospheric pressure (W99) has a flat psd (-1.7 db/octave).
In conclusion, tilt signals recorded at DMB are more strongly affected by the thermal effects than at OLB in the diurnal-semidiurnal band, while substantial differences are not observed in the long period (fortnightly to monthly); the pressure does not seem to influence them in the long period.

\section{Thermal decorrelation of tiltmetric signals}

The primary role that the temperature changes have over the signals acquired by the surface tiltmetric stations is clear since, besides modifying the volume of the electrolytic liquid inside the bubble (whose effect is however compensated by some constants taken into account during pre-processing) (AGI, 1995), they tend to deform the ground in an unpredictable way due to its heterogeneity and thermal inertia. As the thermo-elastic deformation of the ground surface layer on the stations location is unknown, the influence of the thermal component can be evaluated and then subtracted only with a statistic approach (Ricco et al., 2003).

Tilt data sequences were submitted to a polynomial regression procedure between the recorded signal and the temperature itself by different steps summarized as follows:

1) Low pass filtering of tilt and temperature signals by IFFT getting time-series with frequencies lower than $1 \mathrm{cpd}$.

2) Searching for the maximum and minimum values in the filtered thermal sequence in order to obtain «n» sub-sequences increasing or decreasing in time.

3) Decomposition of the filtered components in «n» sub-sequences and computation of the third order polynomial regression between each couple $\left(\mathrm{NS}_{n}, \mathrm{Te}_{n}\right)$ and $\left(\mathrm{EW}_{n}, \mathrm{Te}_{n}\right)$.

4) Computation of the residual values of the filtered components with respect to the corresponding regression polynomials, reassembling of the whole signal, computation of the correlation coefficient $(R)$ and of the standard error of the estimate $(\sigma)$ on each sub-sequence.

Every thermic variation occurring on periods greater than 1 day (step 1) is therefore correlated with the corresponding tilt change but 
only within time intervals in which the temperature either increases or decreases (step 2). If the tilt signal undergoes a large acceleration but the temperature changes lesser, the regression procedure can reduce the signal also of one order of magnitude.

The thermal decorrelation procedure applied to the original tiltmetric series has allowed to correct, within the limits allowed by the method, the ground tilt recorded bringing it back to constant temperature conditions.

\section{Interpretation of decorrelated data}

By comparing the decorrelated signals with the aforementioned procedure for OLB (fig. 6) and DMB (fig. 7) data with the original ones (figs. 3 and 4), it is possible to confirm the period in which the tiltmetric inversion occurred and even anticipate its beginning by 3 days ( 25 instead of 28 of July).

It therefore happens about 10 days before the beginning of a seasonal phase in which the temperature stops rising remaining stationary and afterwards gradually descending (window 63 in figs. 3 and 4).

At OLB between July 25 and November 2 a ground tilt of $39 \mu \mathrm{rad}$ was computed in N55E direction whereas at DMB it amounts to about $2.5 \mu$ radians in N03W direction in the time interval July 25-October 28; these values are 11 times lower than the ones originally recorded at the 2 stations. Such a result is due to the correction procedure strongly reducing the amplitude of the recorded tilt.
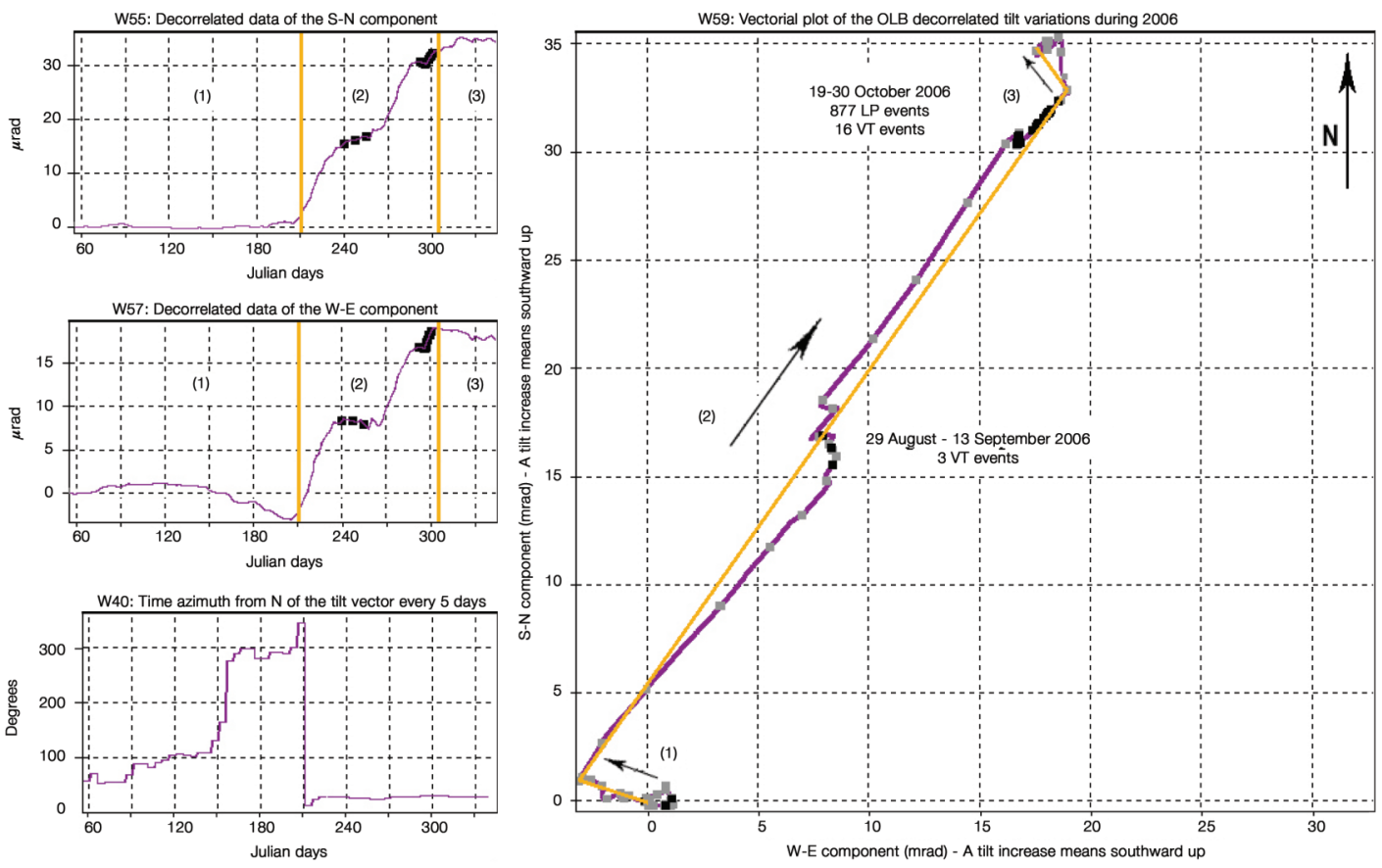

Fig. 6. Working sheet of OLB showing the decorrelated tilt. Windows 55 and 57 show in violet the reassembled sequences of decorrelated data of the NS and EW tilt components. Yellow lines delimit the sectors before, during and after the inversion. Window 40 computes the time azimuth from $\mathrm{N}$ of the tilt vector every 5 days with respect to the starting value. Window 59 show in violet the resultant vector of the decorrelated sequences with grey squares superimposed every 5 days; yellow lines and black arrows indicate tilt vectors in the 3 sectors. Black squares represent seismic events recorded at STH. 

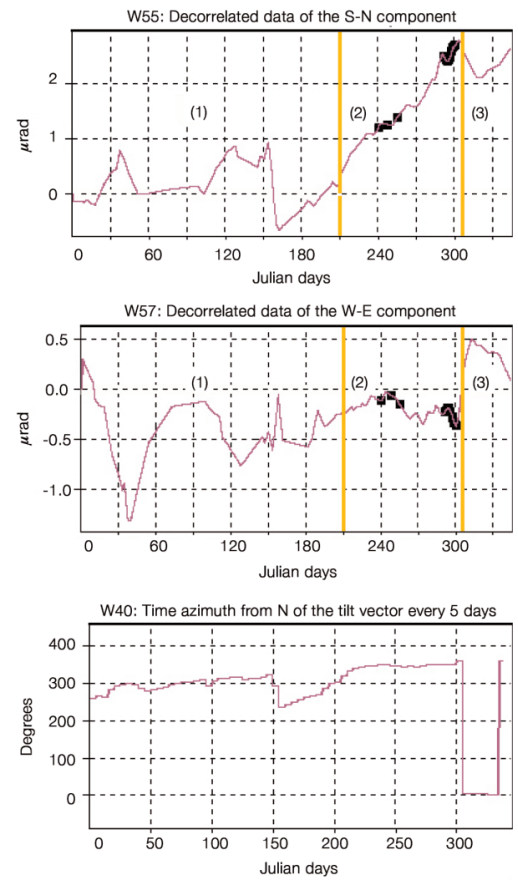

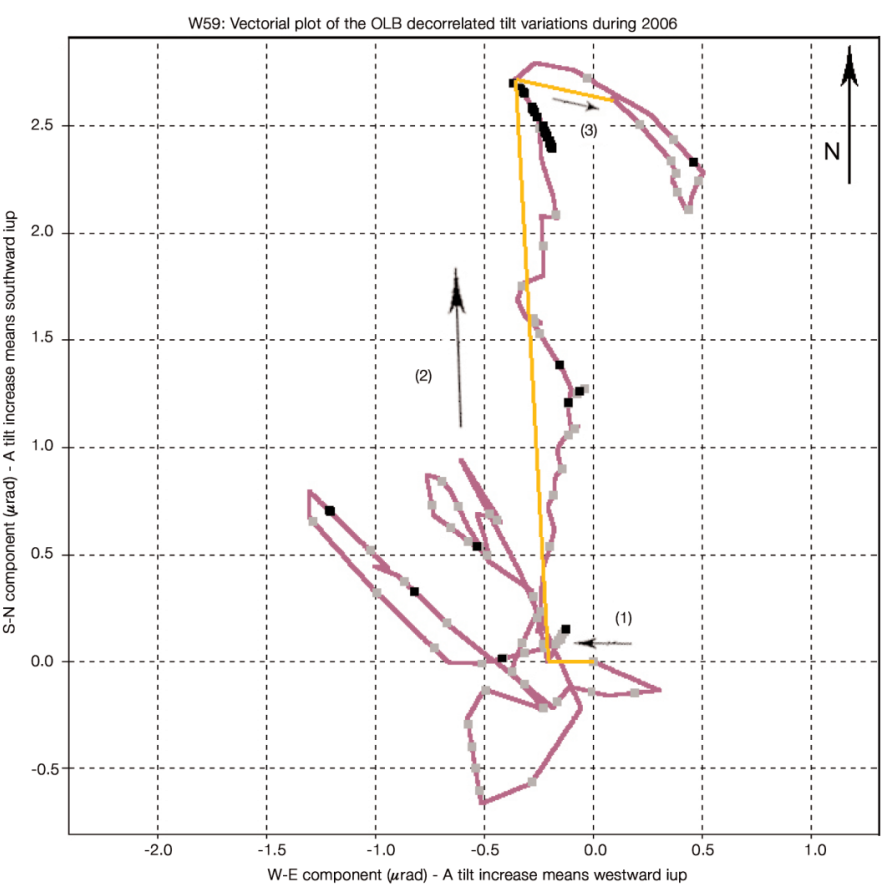

Fig. 7. Decorrelated tilt at DMB (for explanations see fig. 6).

The correct data of DMA and ARC show that between mid-July and December 2006 the ground tilted, respectively, towards NNW (2.7 $\mu \mathrm{rad})$ and $\mathrm{N}(2 \mu \mathrm{rad})$ even if the tilmetric inversion is not so clear as the OLB one.

The tilt computed at OLB is about 15 times greater than that of DMB, DMA and ARC; such a high ratio can be due to the fact that the first station, located eastward with respect to the maximum uplift area, lies in a deformation field whose slope is much higher than the one which is conversely recorded by the other station located northward with respect to the same area.

In fact, in the last 2 years this deformation field locally varied around DMB and OLB and it became more asymmetrical with respect to past.

This statement is based on the study of data acquired during 4 measurements carried out in November 2004, October 2005, March and December 2006 along the Phlegraean coast line and along a SSW-NNE direction (fig. 8). The vertical displacements observed near OLB, located between bm 20 and bm 19A, are $11 \mathrm{~mm}$ in the period 11/2004-12/2006 while near $\mathrm{DMB}$, located between bm $82 \mathrm{~B}$ and $82 \mathrm{~A}$, is only $1 \mathrm{~mm}$; moving south, however, the observed displacement is $9 \mathrm{~mm}$ (section 82B-32) (fig. 8).

To quantify the displacement field dishomogeneity, its slope was evaluated along 5 profiles, 2 of which pass close to DMB and 3 close to OLB, only considering the bm best aligned (fig. 9). For each profile, the vertical displacements (always referred to November 2004) of any bm with respect to the following one were divided by their distance (fig. 9). The derivatives thus obtained are obviously very large close to OLB. In the period 11/2004-12/2006 a tilt of $24.8 \mu \mathrm{rad}$ (in modulus) was observed in the section 2019A (profile WSW-ENE), $19.7 \mu \mathrm{rad}$ in the section 19A-21 (profile ESE-WNW) and $22.9 \mu \mathrm{rad}$ in the section 20-68A (profile SW-NE). In the same periods the tilt computed close to DMB is smaller, varying from $9.8 \mu \mathrm{rad}$ in the section 81 - 
82B (profile SE-NW) to $3.5 \mu \mathrm{rad}$ in the section 82B-82A (profile SSW-NNE).

The slope of the displacement field of deformation therefore assumes an important role in the interpretation of the tilt data. In fact, whereas its mean value is $12.5 \mu \mathrm{rad}$ in a ray of $3-5 \mathrm{~km}$ around Pozzuoli, major deviations are observed in some areas. In the neighbourhood of OLB a value which is about twice the mean one was observed while close to DMB it was about 4 times smaller. In the time interval 3/2006-12/2006 the vertical displacement at OLB is $9 \mu \mathrm{rad}$ while at
DMB is zero; it must be taken into account that DMB is located just on the limit of the La Starza block, a marine terrace that is the most uplifted part of the caldera floor (Orsi et al., 1999) and so it is affected by a different dynamics from that of the east area of Pozzuoli.

The ground inclination at OLB remains however 4 times greater than that computed from levelling data and this anomaly can be explained from the presence of a structural discontinuity whose near-field effect could induce a greater deformation.
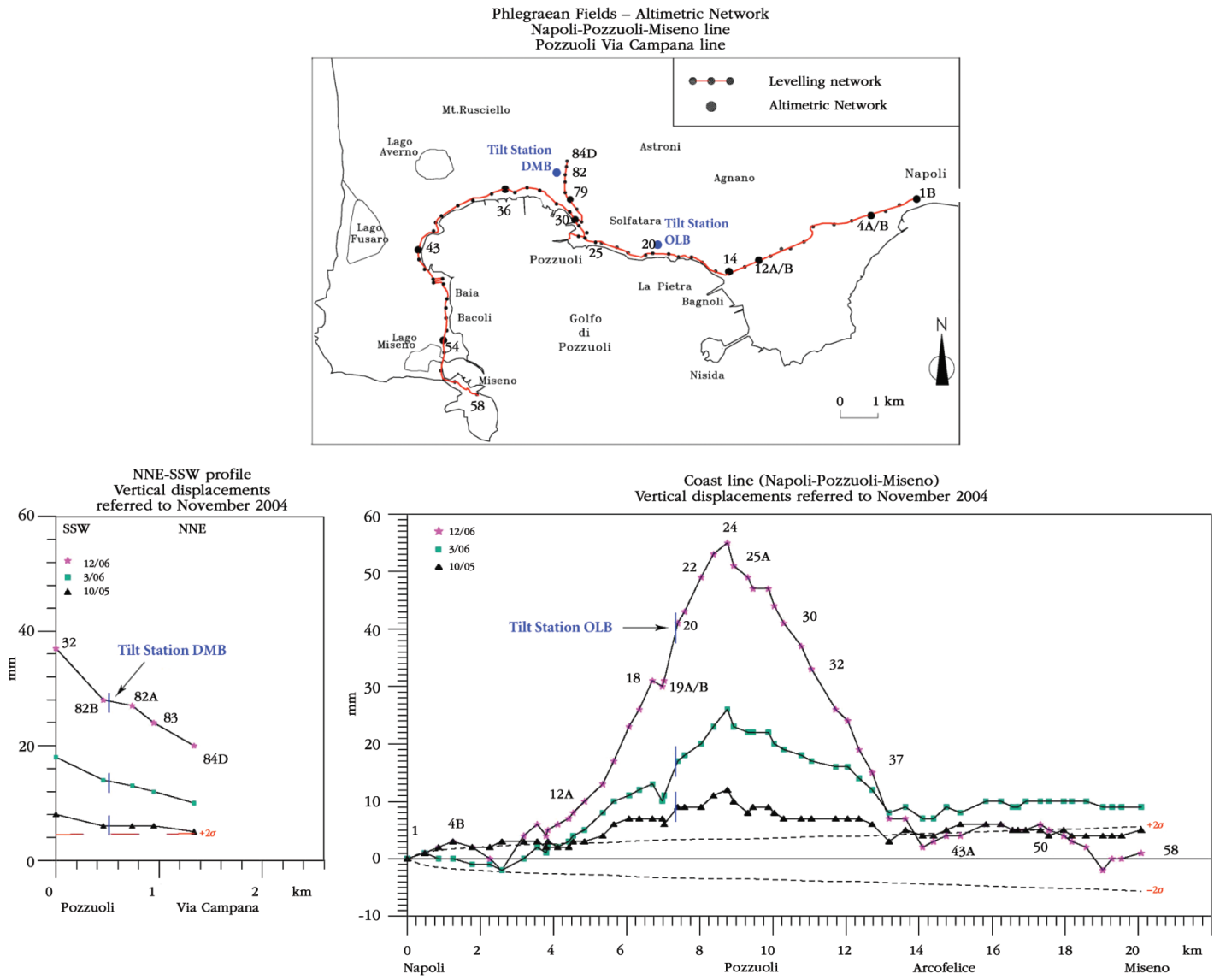

Fig. 8. The top picture shows part of the altimetric Phlegraean network (Coast Line and Via Campana Line); the other 2 show the height variations measured along these lines in November 2004, October 2005, March and December 2006. The tilt stations are represented in blue. 


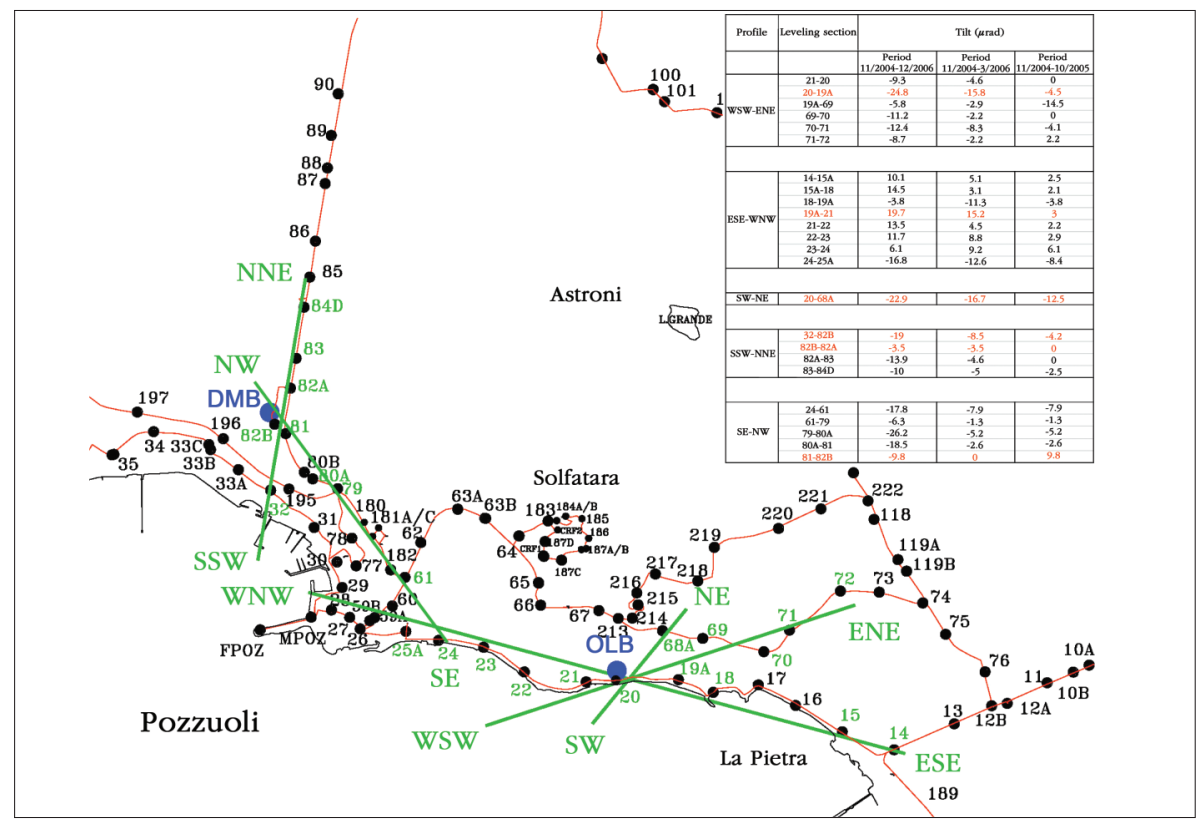

Fig. 9. Zoomed area in the neighbourhood of Pozzuoli showing levelling line and 5 profiles, 2 of which pass close to OLB; both the profiles and the best aligned bm are shown in green. Inserted table contains the gradients computed for every section in the 3 time intervals considered.

\section{Comparison between the tiltmetric signals and the recorded seismic events}

In the time interval between October 19 and 30, the STH seismic station (Tennis Hotel seismic station, fig. 1) recorded $166 \mathrm{VT}$ events with a Magnitude between -1.1 and 0.8 while in the period October 23-29 SOB (Solfatara Broadband station, fig. 1) recorded $877 \mathrm{LP}$ events as well. Most of these earthquakes were located in the surroundings of the Solfatara crater at a depth between 1 and $2 \mathrm{~km}$.

The earthquakes sequence recorded at STH was superimposed on the tilt, the temperature and the baric signals of OLB and DMB; from the analysis of the graphs it is evident they happened in the last days before the end of the tiltmetric inversion recorded at OLB (figs. 3 and 6).

The same procedure was applied for 3 more events recorded at STH between August 29 an September 13 but with a Magnitude between
0.4 and 0.6 ; it was noticed they happened when, during the inversion phase, ground tilt decreased in velocity while its direction suddenly rotated $55^{\circ}$ counter-clockwise, moving to north and afterwards to the previous azimuth (fig. 6).

At DMB, on the contrary, nothing significant has been pointed out during the seismic activity (fig. 7).

As is known, the VT events indicate the faulting of brittle rock as a consequence of pressurization induced by the arrival of a batch of magma while the LP events are volcano-related earthquakes of low frequency associated with vibrations of a fluid-filled crack.

It is difficult to quantify the cause-effect relationship between the rotation of the tilt observed at OLB and the presence of seismic activity of low energy concentrated in Solfatara (which is about $1 \mathrm{~km}$ from this station). The common cause of the 2 phenomena is based however on the unrest phase that started in 
2004, responsible for the deformation pattern modulated by local structures, and triggering seismicity in an intensely fractured area as the Solfatara.

According to a recent interpretative model (Saccorotti et al., 2007), at the base of all the geophysical events observed at the Phlegraean Fields in the last 2 years, there has been a gradual accumulation of fluids to the top of a magmatic chamber at least 3-4 km deep.
The overpressure induced by the magma that rises from deeper zones furnishes energy to the uplift and is also responsible for fracturing the rocky rigid layer overlying the same camera and therefore the VT events.

After reaching critical levels, the fluids ascend through the hydrothermal system located above the rigid layer and the fast pressurization of the fractures give rise to their resonance (LP events in October 2006).

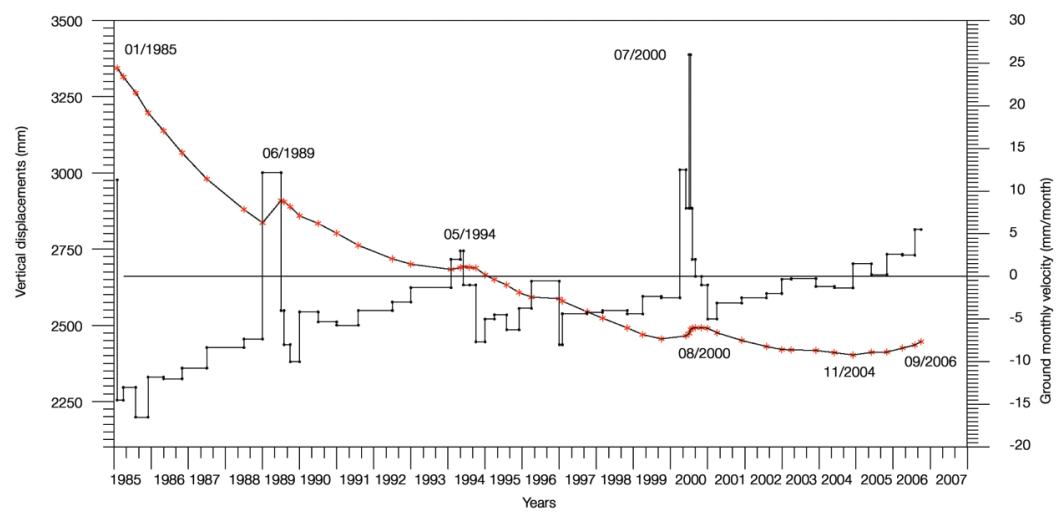

Fig. 10. Height variations (in red) at bm 25A: the different phases of the inversion of ground motion from 1989 to 2006 are clearly visible. The ground monthly velocity is shown in black.

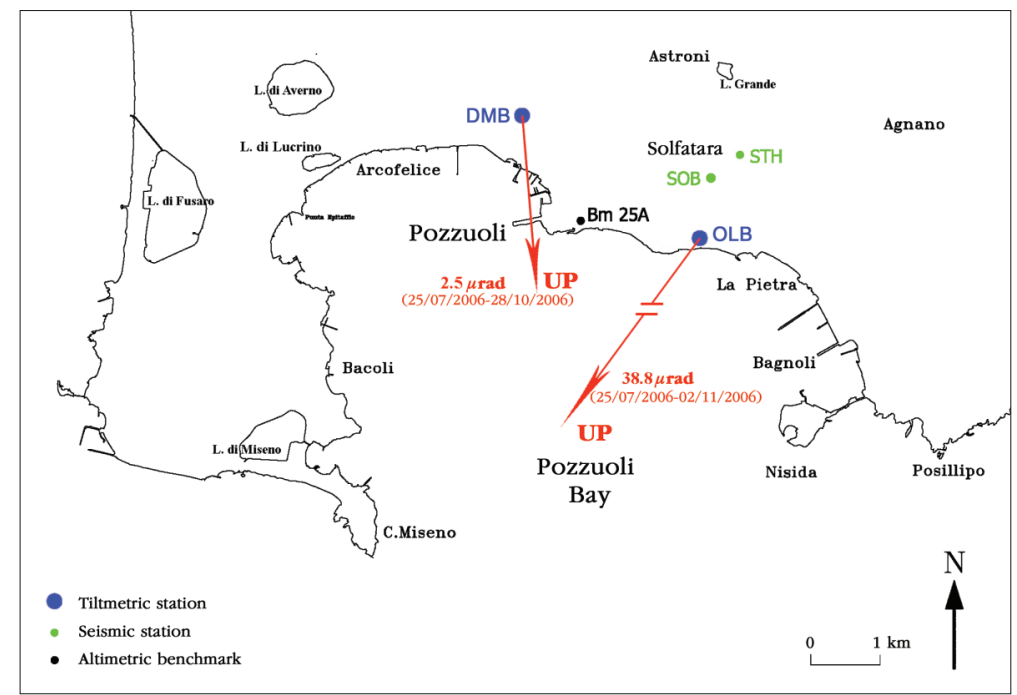

Fig. 11. Layout of the tilt and seismic stations. The vectors plotted (not in scale) point towards the rising area. 
The ground deformation preceding crack growth is likely to be the one recorded by tiltmeters.

\section{Conclusions}

The Phlegraean bradyseism from the end of the last strong uplift phase (1982-1984) has been characterized by a descending phase of ground motion, interrupted by short uplift phases during Spring 1989 (Luongo et al., 1989; Ricco et al., 1991), August 1994 (Ricco et al., 1994) and during Spring-Summer of 2000 (Berardino et al., 2002; Borgström et al., 2006), lasting a few months but characterized by remarkable deformation velocity (fig. 10). The end of these crises was always marked by an initial increase in the subsidence velocity followed by a slow velocity decrease up to the conditions before the crisis itself.

From Summer 2004 a new uplift phase started with very different features with respect to the previous ones, showing small accelerations and stases of the phenomenon. The uplift recorded during July 2006 (fig. 11) is related to this phase of slow unrest but differs from the previous ones for the amount of the angular deformation reaching about $40 \mu \mathrm{rad}$ eastward with respect to the maximum uplift area (OLB tilt station).

Another 3 stations (DMB, DMA and ARC) located N-NNW to Pozzuoli recorded the miniuplift even if lesser (2-3 $\mu \mathrm{rad})$.

The gradient inferred from altimetric measurements carried out between March and December 2006 is lower than the instrumentally recorded one.

This inconsistency is only apparent because the displacement field measured is not homogeneous since it is modulated by local structures that change its slope: it should be in 2 years less than $20 \mu \mathrm{rad}$ for a source at $3 \mathrm{~km}$ depth and for $5 \mathrm{~cm}$ uplift, as predicted by a global inflation model (e.g., Mogi).

Moreover, seismic activity was recorded during a sudden change of velocity and direction of the ground tilt and many local small earthquakes recorded between October 19 and 28 inside the Solfatara crater preceded by a few days the end of the uplift.

\section{REFERENCES}

AGI (APPlied GeOMECHANICS InCORPORATED) (1995): Tiltmeter temperature coefficients: source, definition and use to improve accuracy, Technical Rep. n. B-95-1005, Rev. C.

Aquino, I., C. Ricco and C. Del Gaudio (2006): Rete Tiltmetrica dell'Area Napoletana (www.ov.ingv.it/italiano/pubblicazioni/openfile/ofr_04_06.htm).

Berardino, P., S. Borgström, G. Cecere, C. Del Gaudio, P. De Martino, G. Fornaio, R. LAnari, G.P. RicciarDi, C. Ricco, E. Sansosti, V. Sepe and V. Siniscalchi (2002): Un approccio multimetodologico per il controllo delle deformazioni nell'area flegrea, in Atti della VI Conf. Naz. dell'ASITA, 5-8 November 2002, Perugia, Italy, 1, 409-416.

Berardino P., F. Casu, G. Fornaro, M. Manunta, M. Manzo, A. Pepe, S. Pepe, E. Sansosti, F. Serafino, G. Solaro, P. TizZANi and G. ZENi (2007): A two-scale ground deformation analysis by exploiting ENVISAT radar data via the SBAS DInSAR technique: the Campi Flegrei case study, in Proceedings of the ESA ENVISAT Symposium, 23-27 April 2007, Montreaux, Switzerland (on CD-ROM).

Berrino, G., G. Corrado, G. LuONGO and B. Toro (1984): Ground deformation and gravity changes accompanying the Pozzuoli uplift, Bull. Volcanol., 47, 187-200.

Borgström, S., I. Aquino, C. Del Gaudio, P. De Martino, C. Ricco, V. Siniscalchi, G. Solaro, P. Tizzani and G.P. RicCIARDI (2006): A new approach for ground deformation monitoring in volcanic areas: the case of the Phlegraean Fields (Naples, Italy), in Atti del III Workshop AIT sul Telerilevamento a Microonde, 25-26 Novembre 2004, Napoli, Italy, Riv. Ital. Telerilev., 35, 7-19.

Corrado, G., I. Guerra, A. Lo Bascio, G. LuONGO and F. RAMPOIDI (1977): Inflation and microearthquake actvity of Phlegraean Fields, Italy, Bull. Volcanol., 40 (3), 169-188.

DAL Moro, G. and M. ZADRO (1998): Subsurface deformations induced by rainfall and atmospheric pressure: tilt/strain measurements in the NE-Italy seismic area, Earth Planet. Sci. Lett., 164, 193-203.

HARRISON, J.C. (1976): Cavity and topographic effects in tilt and strain measurements, J. Geophysic. Res., 81, 319-328.

Lanari, R., P. Berardino, S. Borgström, G. Del Gaudio, P. De Martino, G. Fornaro, S. Guarino, G.P. Ricciardi, E. SANSOSTI and P. LUNDGREN (2004): The use of IFSAR and classical geodetic techniques for caldera unrest episodes: application to the Campi Flegrei uplift event of 2000, J. Volcanol. Geotherm. Res., 133, 247-260.

Luongo, G., C. Del Gaudio, F. Obrizzo and C. Ricco (1989): Deformazione del suolo dell'area flegrea durante la fase di bradisismo discendente 1985-1989, Boll. GNV, 1, 327-343.

Orsi, G., L. Civetta, C. Del Gaudio, S. DE Vita, M.A. Di Vito, R. Isaia, S.M. Petrazzuoli, G.P. Ricciardi and C. RICCO (1999): Short term ground deformations and seismicity in the resurgent Campi Flegrei caldera (Italy): an example of active block-resurgence in a densely populated area, J. Volcanol. Geotherm. Res., 91, 415-451.

Orsi, G., M.A. Di ViTO and R. IsAIA (2004): Volcanic hazard assessment at the restless Campi Flegrei caldera, Bull. Volcanol., 66, 517-530. 
Ricco, C., C. Del Gaudio, F. Obrizzo and G. Luongo (1991): Misurazioni delle variazioni delle inclinazioni del suolo ai Campi Flegrei, in Atti X Convegno GNGTS, Roma, Italy, II, 1003-1012.

Ricco, C., C. Del Gaudio, G.P. Ricciardi and L. Civetta (1994): Rapporto sulla crisi bradisismica del 23-26 Agosto 1994, Technical Rep. Oss. Vesuviano, Settembre 1994

Ricco, C., I. Aquino and C. Del Gaudio (2003): Ground tilt monitoring at Phlegraean Fields (Italy): a methodological approach, Ann. Geophysics, 46 (6), 12971314.

Ricco, C., I. Aquino, S. Borgstrom, C. Del Gaudio, G.P. RiCCIARDI and P. TIZZANI (2005): Recent evolution of ground deformation at Phlegraean Fields detect by continuous monitoring system via tiltmetric techniques and comparison with high precision, in Atti del XXIV
Convegno Nazionale GNGTS, 101-104.

Saccorotti, G., S. Petrosino, F. Bianco, M. Castellano, D. Galluzzo, M. La Rocca, E. Del Pezzo, L. ZaCCARELLI and P. CUSANO (2007): Seismicity associated with the 2004-2006 renewed ground uplift Campi Flegrei caldera, Italy, Phys. Earth Planet. Interiors, 165, 14-24.

Westerhaus, M. and W. Welle (2002): Environmental effects on tilt measurements at Merapi volcano, Bull. Inf. Marees Terr., 137, 10917-10926

WyatT, F.K., S.T. Morissey and D.C. Agnew (1988): Shallow borehole tilt: a reprise, J. Geophysic. Res., 93, 9197-9201.

(received July 5, 2007; accepted November 22, 2007) 